\title{
SMART CITIES AND MODERN VIEWS ON CITIZEN SECURITY Michal Peňaška ${ }^{1}$, Viktor Šoltés ${ }^{2}$, Andrej Vel'as ${ }^{3}$
}

\begin{abstract}
Modern times bring with them modern approaches to the perception of our problems. The perception of security in cities is no exception. The establishment of general indicators is needed to improve the evaluation and comparison of sites. These security indicators can be found in the six basic characteristics that make up a Smart City. This article contains a proposal for an application and a procedure for assessing the impact of projects on the security of citizens. The present proposal uses a system approach method using some specificities of the ISO 31000 standard. The principle of the proposal is that the probability of risk is a priority and we perceive the consequence as the expected increase and decrease in the level of security in cities.
\end{abstract}

UDC Classification: 352, DOI: https://doi.org/10.12955/pss.v1.68

Keywords: smart, city, security, safety, cities

\section{Introduction}

The issue of the so-called "Smart Cities" has become a topical issue in recent years in the world. This trend initially developed only in the cities of the more developed countries of the world, including the western and northern countries of Europe. The issue of building smart cities can be considered an interdisciplinary issue, as it affects a number of scientific disciplines and affects various areas of life. One of its components is security and the safety of citizens. This should ideally be addressed at all levels of the city.

The aim of this research was to design a procedure that uses the principles of risk assessment according to the ISO 31000 standard and the principles of the Smart City concept. This is so that the potential impacts of projects in cities are assessed in accordance with the principles of strategic planning in cities. The aim is to create a procedure that respects the long-term goals of the city.

\section{Smart cities and new approaches}

For us, the term "smart city" should primarily be a tool for effective urban management, increasing the quality of life and thus increasing the satisfaction of city residents. Unfortunately, this area is the target of "attacks" by the marketing activities of a number of commercial entities, which often create a very unrealistic or simplified view of the issue. This, in the end, hurts the popularization of smart cities itself. We therefore consider it very counterproductive to promote definitions of the concept of a smart city based primarily on state-of-the-art technologies and to evoke some unjustified need for cities to use them. A smart city is by no means just a client of various providers. The city should strive to achieve the set goals very carefully, especially using the resources already available. Subsequently, only when necessary, it is possible to consider solving the problem with a new technology or service. At the same time, it should always be in line with the stated vision and support for the universality of the whole system.

A specific area in the creation of smart cities remains security, which still suffers from a lack of information. At the Faculty of Security Engineering, University of Žilina, we focus on the issue of protection of persons and property (Vel'as, 2019), where we often rely on technological elements in security, so we test them (Vel'as et al., 2017) in the article "Influence of changing the parameters of the camera system on video-based motion detection" and assess their suitability for security practice. We also do research on transport safety, such as described by Vel'as and Svetlík (2016) in the article "Design of equipment to improve safety on roads". In the case of the city, education is becoming an important prerequisite in the effort to improve the lives of its inhabitants. It is important to educate the city and its inhabitants so that the new measures on both sides are understood and tolerated. This ultimately creates "fertile ground" not only for the implementation of new security solutions, but also for their meaningful use. Thanks to this, the city can avoid misunderstanding its steps.

\footnotetext{
${ }^{1}$ University of Zilina, Faculty of Security Engineering, Department of Security Managemet, michal.penaska@fbi.uniza.sk

${ }^{2}$ University of Zilina, Faculty of Security Engineering, Department of Security Managemet, viktor.soltes@fbi.uniza.sk

${ }^{3}$ University of Zilina, Faculty of Security Engineering, Head of Department of Security Managemet, andrej.velas@fbi.uniza.sk
} 


\section{The city as an organism}

As Goodall (1987) and Kuper (1996) defined the term "city" years ago, it is a large human settlement. It can be defined as a permanent and densely settled place with administratively defined boundaries whose members work primarily on non-agricultural tasks (Caves, 2004). The implementation of the concept of smart cities is a big trend in the world. According to Kubás and Štofková (2017), the development of cities has become so significant that today it is difficult to address the requirements of the population so that it is in line with the technological development and the requirements of the population in the 21st century. As Bitušíková (2003) wrote, the city is a complex social organism that differs quantitatively from the village, i. the size of the agglomeration and the number of inhabitants, but also qualitatively - a wide social composition and the complexity of ties and relationships.

\section{Perception of security and safety in cities}

When discussing the issue of perception of safety in cities, it is important to look at it traditionally from two basic perspectives. According to Mišík and Kubás (2017), these are the objective and subjective perception of safety. Each of them has its advantages and disadvantages and may have a different role in the creation of smart cities, or they will be applied together.

As further defined by Gullone and Cummins (2002), objective perception refers to material security, social conditions, physical health, functional condition, or e.g. social status. The quality of life is perceived here as a measure in which the individual uses the possibilities of life, is observable from the outside, evaluable and comparable to others.

Hofreiter (2006) in his publication Securitology argues that the subjective perception of security indicates an awareness of the real threat to security, ignorance or, non-perception of the security threat, awareness of the impossibility of actively facing the threat and also the perception of the threat, which does not really exist, the so-called obsession.

Another author, Finka et al., (2012) in their publication "Safety as the quality of space" states that urban safety can be defined as any type of human safety within a built-up area (urban area) of the city, to which the population has mostly free access (i.e. within public spaces with emphasis on outdoor spaces) and any kind of human security related to his activities in these public spaces.

\section{Security and safety in smart cities}

The place of security in the concept of the smart city is a very complex issue, which we must approach in the same way as the concept of the smart city itself - comprehensively. This issue is all the more complicated when we look at safety in the six basic characteristics of Smart City. Giffinger et al. (2007) in the technical report "Smart cities - Rankings of European medium-sized cities" define the basic characteristics of smart cities and their factors and indicators. These six basic characteristics are:

\section{Smart Economy}

In accordance with the concept of a smart city, Smart Economy aims to increase productivity and modernize production processes. It uses the principles of the "knowledge economy" and innovation, which are key to promoting sustainable business and trade. Closely related to this is the support of research and development, business and investment in the city.

The factors that make up this characteristic are: Innovative spirit, Entrepreneurship, Economic image and trademarks, Productivity, Labor market flexibility, International integration and the Ability to transform. (Giffinger 2017)

From a security point of view, we perceive this characteristic also through risks towards business or of an economic nature. The economy plays a significant role in creating social conditions and can be a significant criminogenic factor. It is therefore important to take security into account precisely in measures related to the solution of economic and business environment development, to prevent its possible secondary consequences, such as e.g. the emergence of crime.

Šltés (2017) deals more with the issue of socio-economic impacts on the safety of citizens. It is important to set indicators of the prosperity of individual sectors so that we can indicate trends in time. Rapid response e.g. in the form of the city's investments in certain sectors, is key in ensuring a healthy city economy. 


\section{Smart People}

Smart People are those who have access to knowledge and their own development. In a smart city, the inhabitants participate in the development of the city through their own activities. This is either in the form of business or any other form of involvement in public life. Factors of this characteristic are: Level of qualification, Lifelong learning, Social and ethnic plurality, Flexibility, Creativity, Cosmopolitanism/Openness and Participation in public life (Giffinger, 2017).

Modern and intelligent solutions require modern and intelligent users. And this is exactly the ideal state that the city should strive for. In the modern world, education is also perceived as a way to alleviate social tension.

This is an important topic when looking at the current global social mood in the themes of ethnicity and cosmopolitanism. This often carries security risks. The city should therefore also focus on building tolerant citizens carrying out activities not only for the benefit of the city, but also for other residents.

\section{Smart Governance}

Smart Governance is primarily "smart public administration", sometimes mistaken for E-Government, it consists mainly of a transparent management system. The city should allow residents to participate in the planning and decision-making process. It should ensure open access to information, the so-called "Open data", e.g. through publicly available information systems. Factors of this characteristic are: Participation in decision-making processes, Public and social services, Transparent governance and Policy strategies and perspectives (Giffinger, 2017).

It is very convenient when the data is made available to users for various analyzes. Their users can be not only the city, but also an ordinary person, or business entities and universities. It is necessary to consider the extent and what information to allow open access to so as to prevent its misuse and ensure effective usage.

The system should also act preventively against inefficient management of the city, or corruption. Increasing the awareness of the population and enabling the population to participate in decision-making processes leads to mutually beneficial solutions to problems. Some data can have a big impact on the mood in a society, which can be reflected in a reduced subjective sense of quality of life.

\section{Smart Mobility}

Smart Mobility is "smart transport" and aims for safe, sustainable and efficient mobility in the city. Today, various modern technologies and information systems significantly help. Efforts should also be made to mitigate the negative effects on the environment, in particular by looking for alternatives to traditional motor transport.

This is a much-discussed topic both in terms of congestion of transport sections and in terms of reducing the negative impact on the environment. The factors of intelligent mobility are: Local accessibility, International accessibility, Information and communication technologies of transport infrastructure and Sustainable, innovative and safe transport systems (Giffinger, 2017).

Many cities are becoming increasingly aware of the alarming state of traffic associated with urban development. The current infrastructure in many cities no longer catches up with the current traffic intensity. In many cases, this results in a reduction in security and is reflected in a high number of incidents of various kinds. Negative effects on human health and the environment are also dangerous. It is important to set up transport infrastructure and its use in the city so that these risks are reduced.

\section{Smart Environment}

A Smart Environment according to Colldahl et al. (2013) is one that emphasizes the sustainable development of the city with the intelligent use of resources. It can use elements of energy management, which emphasizes recycling, resource substitution, alternative energy sources and pollution reduction. Efficient waste management, the sewerage system and the water supply system should also take care of this. A smart city should strive to save energy through technological innovation.

These innovations should ensure lower consumption and higher efficiency of energy use. Factors of this characteristic are: Attractiveness of the natural environment, Pollution, Environmental protection and Sustainable management of resources (Giffinger, 2017). 
A clean environment should not only have an aesthetic character, but also have a significant impact on people's health and well-being. We can perceive safety here in the form of environmental safety.

A smart city should create the conditions for its increase and should also have a positive impact on the city's inhabitants. They should educate them towards responsible behavior for the rational consumption of resources. Irresponsible behavior can create a hazardous environment for life. In this case, there are greater risks in the form of lung diseases, cancer, etc. The city's costs for a cleaner and healthier environment can thus also save on healthcare costs.

\section{Smart Living}

Smart Living is a characteristic striving for a modern way of life, responsible behavior and conscious consumption. It is intended to provide safety, health care and the improvement of living space. Factors of this characteristic are: Cultural facilities, Health care, Individual safety, Quality of housing, Educational facilities, Tourist attractiveness and Social cohesion (Giffinger, 2017).

Of these factors, the "Individual Security" factor is probably the most important for security and safety. The city should strive to reduce crime and create a safe environment for life through security measures. In larger cities, this is most often done by setting up a city police force, which is responsible for security in the city. In terms of the smart city concept, it is necessary to abandon the traditional approach focused primarily or only on CCTV. The latest technologies already offer us a number of other means. Their appropriate design and mutual combination is crucial in increasing safety in public spaces or residential areas.

\section{Methodology}

The proposal was preceded by an assessment of the suitability of different methods and approaches and their principles that could be used to develop a risk assessment process for urban projects in relation to the safety of citizens.

The system approach and management methods and project management methods was used in this research. The way of perceiving the issue is through the theory of security management and crisis management. The proposed solution is inspired by some parts from the ISO 31000 standard.

The present proposal also supports the theory of smart cities. It takes over the basic 6 characteristics of this concept, which are becoming areas of security. The proposal converts the likelihood of risks to the priority of security areas and converts the consequences into the expected impact and intensity. This intensity can be positive or negative. This provides a better view of the security implications of the implemented projects in the environment. An application design to support this procedure is created in Microsoft Excel software. Basic mathematical formulas and simple macros are used.

\section{Practical use of security indicators}

Compiling a set of several indicators is an important part of monitoring the city's long-term goals. We can divide the city into several areas that we can monitor. Various international institutions are developing their own sets of indicators to assess large cities. The city can thus decide whether to strive to improve these areas according to what has been set by a recognized international institution or to set its own goals as well as indicators for them.

Using the mentioned indicators, a city index is then created. This means that we will rate the city in this way according to how successful it is in the given area. International institutions then evaluate cities each year and set their indices. They then publish these results. It can be, for example, the Smart City Index or in the field of security it is the Safe City Index.

One of the entities that creates indicators for the evaluation of the Safe Cities Index is the international magazine The Economist. For these purposes, The Economist magazine created the so-called "Intelligence Unit". It is the research and analytical division of The Economist Group, which is a sister company of The Economist magazine.

This unit annually evaluates approximately 60 world cities according to 57 indicators of the Safe Cities Index. These indicators are divided into four areas (digital security, health security, infrastructure security and personal security). 


\section{Assessment of personal security}

For illustration, Figure 1 uses indicators to assess the security of citizens according to The Economist Intelligence Unit. We can use them for our own evaluation methods. Then we do not evaluate these areas exactly according to the methodology of the mentioned institution, but we can create our own methodology.

\begin{tabular}{|c|c|c|c|c|c|c|c|c|}
\hline \multirow{3}{*}{$\begin{array}{c}\text { CITIZENS 'SECURITY INDICATORS } \\
\text { Level of police engagement }\end{array}$} & \multirow{2}{*}{\multicolumn{3}{|c|}{$\begin{array}{c}\text { PRIORITY } \\
(0=\text { min; } 5=\text { max })\end{array}$}} & \multicolumn{4}{|c|}{ IMPACT AND INTENSITY } & \multirow{3}{*}{$\begin{array}{c}\text { OVERALL IMPACT } \\
x>0=\text { better; } x<0=\text { worse; } x=0=\text { no change } \\
1\end{array}$} \\
\hline & & & & \multicolumn{2}{|l|}{ Impact type: } & \multicolumn{2}{|c|}{ Intensity: } & \\
\hline & $<$ & > & 1 & Better & $\nabla$ & $<$ & $>1$ & \\
\hline Community-based patrolling & $<$ & > & 1 & Better & $\nabla$ & $<\quad>$ & 4 & 4 \\
\hline Available street-level crime data & $<$ & $>$ & 1 & Without change & $\nabla$ & $<\quad>$ & $>2$ & 0 \\
\hline Use of data-driven techniques for crime & $<$ & $>$ & 1 & Worse & $\nabla$ & $<\quad>$ & $>4$ & -4 \\
\hline Private security measures & $<$ & $>$ & 1 & Better & $\nabla$ & , & 5 & 5 \\
\hline Gun regulation and enforcement & $<$ & > & 1 & Better & $\nabla$ & $<\quad>$ & $>2$ & 2 \\
\hline Effectiveness of the criminal justice system & $<$ & > & 1 & Worse & $\nabla$ & $<\quad>$ & $>4$ & -4 \\
\hline Political stability risk & $<$ & $>$ & 1 & Worse & $\nabla$ & $<\quad>$ & $>2$ & -2 \\
\hline Hazard monitoring & $<$ & $>$ & 1 & Better & - & $<\quad>$ & $>4$ & 4 \\
\hline Prevalence of petty crime & $<$ & > & 1 & Better & $\nabla$ & $<\quad>$ & $>1$ & 1 \\
\hline Prevalence of violent crime & $<$ & > & 1 & Without change & $\nabla$ & $<$ & $>1$ & 0 \\
\hline Organised crime & $<$ & > & 1 & Better & $\nabla$ & $<\quad>$ & 4 & 4 \\
\hline Level of corruption & $<$ & $>$ & 1 & Better & $\nabla$ & $<$ & 2 & 2 \\
\hline Rate of drug use & $<$ & $>$ & 1 & Better & $\nabla$ & $<$ & 1 & 1 \\
\hline Frequency of terrorist attacks & $<$ & $>$ & 1 & Better & $\nabla$ & $<\quad>$ & 3 & 3 \\
\hline Severity of terrorist attacks & $<$ & $>$ & 1 & Better & $\nabla$ & $<\quad>$ & 3 & 3 \\
\hline Gender safety (female homicide) & $<$ & > & 1 & Without change & $\nabla$ & $<$ & 1 & 0 \\
\hline Perceptions of safety & $<$ & $>$ & 1 & Better & $\nabla$ & > & 5 & 5 \\
\hline Threat of terrorism & $<$ & $>$ & 1 & Worse & $\nabla$ & > & $>4$ & -4 \\
\hline Threat of military conflict & $<$ & $>$ & 1 & Better & $\nabla$ & $<$ & 2 & 2 \\
\hline Threat of civil unrest & $<$ & $>$ & 1 & Better & $\nabla$ & $<\quad>$ & 4 & 4 \\
\hline SUM: & & & 21 & & & & 59 & 17 \\
\hline
\end{tabular}

The analysis of the use of indicators for the assessment of security in cities is one of the main tasks of Michal Peňaška's scientific activities within his doctoral study at the Faculty of Security Engineering. Figure 1 shows an example of how indicators can help us. As mentioned above, it is not so important for us in this example whether we take the indicators from an institution or not. We can create our own set of indicators that will suit the goals we need.

It is also important to say that we do not have to evaluate the city as a whole, but we can use this methodology to evaluate the city's projects before they are launched. We will therefore evaluate how a project or innovation will improve or worsen a specific area of security. We can make this assessment before starting the project, then it would be our expectations of impact. However, we can also evaluate with the lapse of time after the start of the project or after its end.

Step by Step:

1. The first column shows the name of the indicator.

2. The second column sets the priority. It is up to us whether we decide to give some indicators a higher priority. Priority acts as a multiplier of the overall impact. If it is zero, the impact is multiplied by zero, so the rating of the overall impact will be " $0=$ No change".

3. The third and fourth columns are Impact and its intensity. Impact has 3 possibilities: better (multiplication number 1), worse (multiplication number -1), no change (multiplication number $0)$. Then we can also determine the intensity of the expected impact.

4. The last column is the total impact. The larger the number, the greater the improvement we expect. The smaller this number, the greater the deterioration we expect. When this number is zero, it means that there is zero priority or zero impact. The overall impact is automatically colored greenish or reddish.

5. Finally, we can automatically generate a graph that visually shows us where improvement and deterioration can be expected. (Figure 2) 


\section{Data sources for safety assessment}

A very important condition for the successful assessment of the impacts of the project results on the security of citizens in cities is that we set indicators, but also evaluation criteria and data sources for evaluation. In some cases, it is possible to use sources of objective data and in some cases sources of subjective data. We can obtain objective data, for example, from official statistics or from final reports of relevant organizations. Subjective data can be obtained, for example, by a questionnaire survey, which is focused on the subjective perception of security.

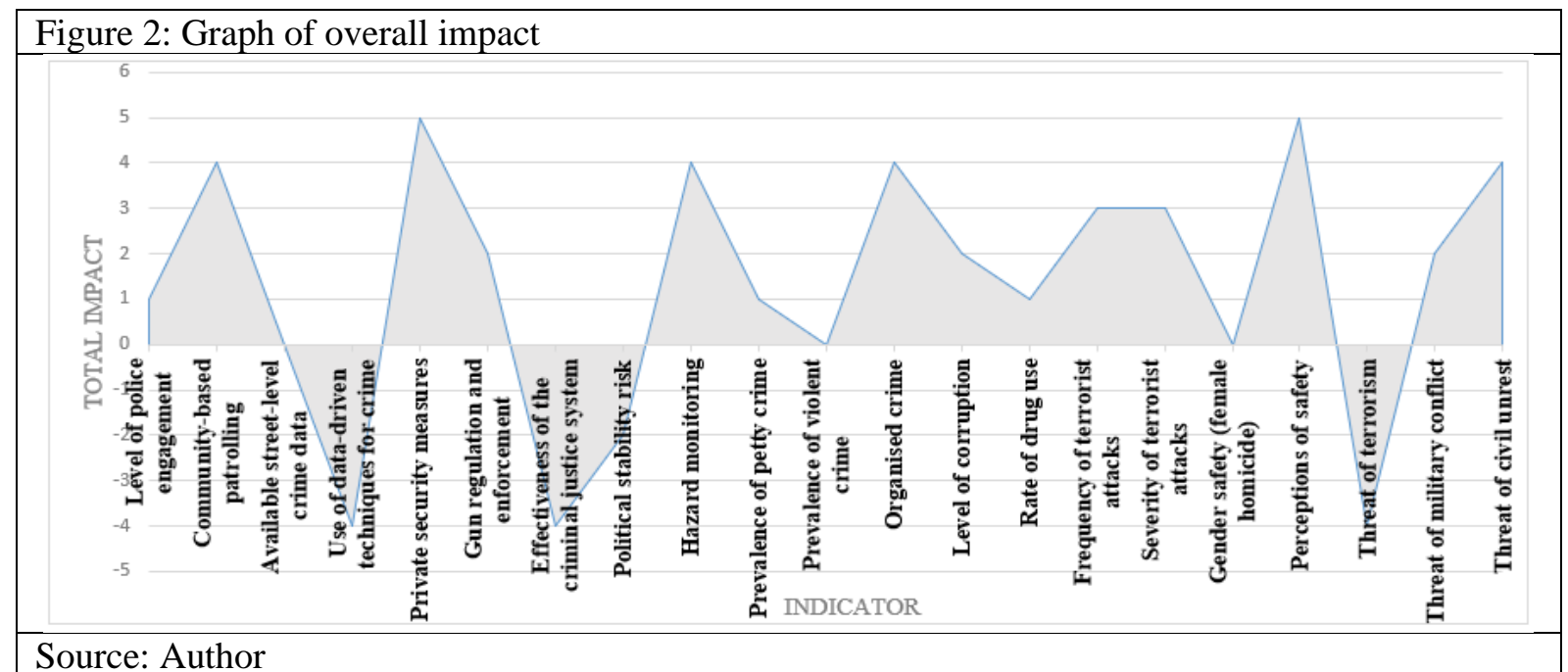

Ideally, this or a similar method will be used before the start of the project, during its course and after the end of the project. This will improve the perception of achieving the goals that are a priority for the city. The following diagram (Figure 3) describes the evaluation process.

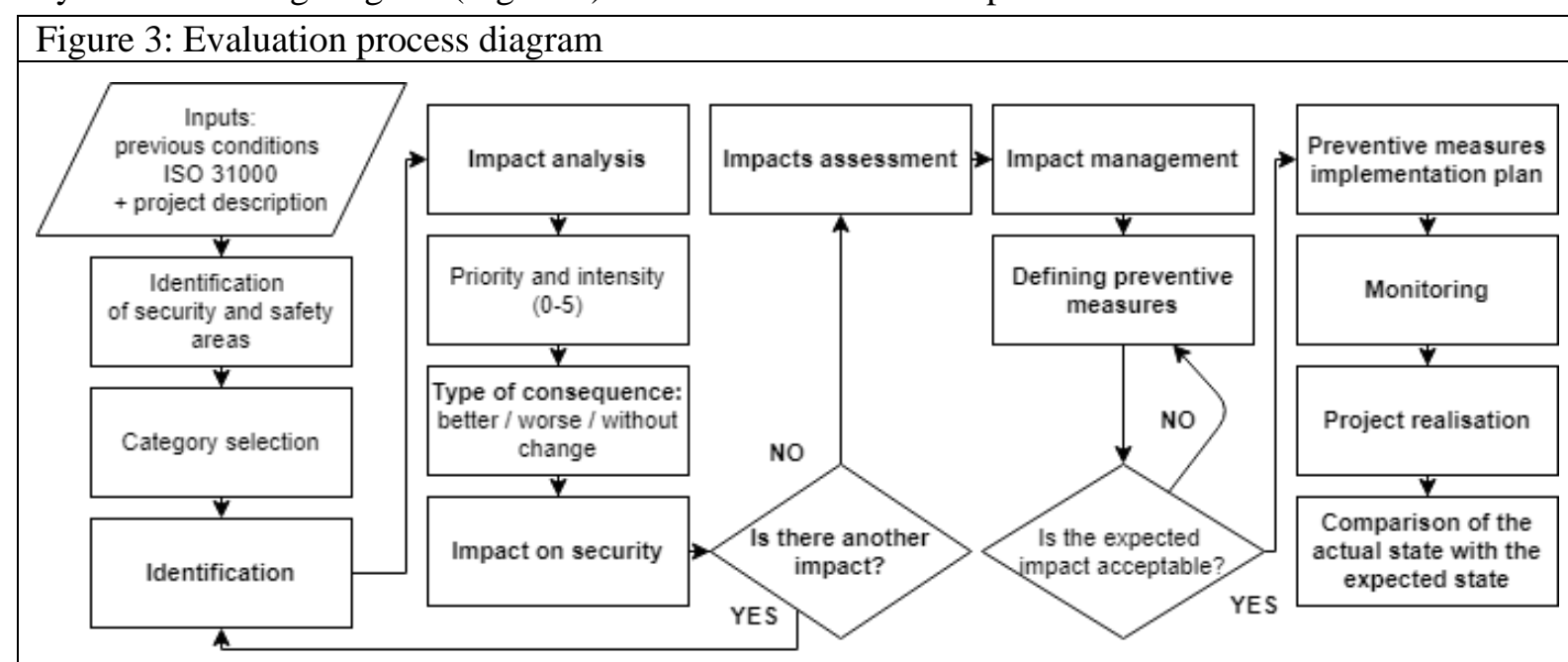

\section{Source: Author}

\section{Conclusion}

The term "smart city" is quite common today. It is important to understand the fact that it is not modern technologies that make the city intelligent. Modern technologies should only be seen as a means to effectively achieve the city's goals, as long as it is relevant to the specification of the problem. Municipalities are constantly changing and evolving organisms. This constantly prepares new challenges for their leadership. Modern concepts of city management, such as the concept of the Smart City (or the Safe City) seeks to build a perspective on the city's problems while maintaining certain meaningful principles. These are e.g. universality, energy efficiency, ensuring sustainable development, etc. In today's dynamic times, we must also learn to create dynamic cities.

It is therefore very good if the city has set long-term goals and a long-term strategy. This strategy should ideally also be designed for security. A suitable method is therefore to compile a set of security indicators 
that are important for the city. The methodologies of recognized evaluation institutions can help in this, or each city will create its own set of indicators. Subsequently, it is important for the city to consider before launching any project how this project may have an impact on specific security indicators. Regular impact assessments bring benefits to the city, especially in better clarity about what we expect from the future or whether the project met our expectations.

\section{Acknowledgment}

VEGA 1/0768/19 - Research on Impacts of the Socioeconomic Development of the Region on the Citizens' Security.

\section{References}

Bitušíková, A. (2003). Čo je mesto? Mesto v predstavách jeho obyvatel'ov. [What is a city? The city in the imagination of its inhabitants]. Etnologický časopis. 2003, vol. 90, no. 3., Retrieved from https://www.jstor.org/stable/42639151?seq=1$\%$ 20page_scan_tab_contents\#page_scan_tab_contents

Caves, R. W. (2013). Encyclopedia of the city. New York, NY: Routledge.

Colldahl, C., Frey, S., Kelemen, J. E. (2013). Smart Cities: Strategic Sustainable Development for an Uran World. Karlskrona, Sweden: School of Engineering, Blekinge Institute of Technology Retrieved from https://www.divaportal.org/smash/get/diva2:832150/FULLTEXT01.pdf

Finka, M. (2012). Bezpečnost' ako kvalita priestoru - úvod do problematiky. [Security as a quality of space - an introduction to the issue.] Bratislava, Slovakia: ROAD/Centrum urbánnej bezpečnosti. ISBN 978-80-88999-40-9.

Giffinger, R., Fertner, Ch., Kramar, H., Kalasek, R., Pichler/Milanović, N., Meijers, E. (2007). Smart cities - Rankings of European medium-sized cities. [Technical Report]. Vienna, UT: Centre of Regional Science. Retrieved from https://www.researchgate.net/publication/261367640_Smart_cities_-_Ranking_of_European_medium-sized_cities

Goodall, B. (1987) The Penguin Dictionary of Human Geography. London, UK: Penguin Books.

Gullone, E., Cummins, R. A. (2002). The Universality of Subjective Wellbeing Indicators. London, UK: Kluwer Academic Publisher.

Hofreiter, L. (2006). Securitológia. [Securitology]. Liptovský Mikuláš, SK: Akadémia ozbrojených síl generála M. R. Štefánika, 138 p. ISBN 978-80-8040-310-2.

Kubás, J., Štofková, Z. (2017). Application of some research methods to determine the level of safety in municipalities. Procedia - social and behavioral sciences. Vol. 237. p. 242-248.

Kuper, A., Kuper, J. (1996). The Social Science Encyclopedia. 2nd edition. London, UK: Routledge.

Mišík, J., Kubás, J. (2017). Safety management as a support activity in the local self-government. Innovations in science and education : CBU international conference proceedings 2017. Prague, Czech republic: Central Bohemia University, p. 728731.

Šoltés, V., Štofková, K. R., Kutaj, M. (2016). Socio.economic analysis of development of regions. Global Journal of Business, Economic and Management: Current Issues, 6(2), 171-178. Retrieved from https://doi.org/10.18844/

gjbem.v6i2.1382

Vel'as, A., Kutaj, M., Durovec, M. (2017). Influence of changing the parameters of the camera system on video-based motion detection. Madrid, Spain: ICCST 2017 : 51st international carnahan conference on security technology : October 23-26, 2017: IEEE, 2017. - ISBN 978-1-5386-1585-0. - [5] s. - (International carnahan conference on security technology proceedings. - ISSN 1071-6572).

Vel'as, A., et al. (2019). Ochrana osôb a majetku v obciach. [Protection of persons and property in municipalities.] Žilina, SK: Žilinská univerzita, 2019, 186 p. ISBN 978-80-554-1520-8. 